\title{
Antagonistic Efficiency of Aspergillus giganteus as a Biocontrol Agent against Aflatoxigenic Aspergillus flavus Infecting Maize
}

\section{Ramya Krishnamurthy* (D), Palghat Ragunathan Padma and Kavitha Dhandapani}

Department of Biochemistry, Biotechnology and Bioinformatics, School of Biosciences, Avinashilingam Institute for Home Science and Higher education for Women, Coimbatore - 641 043, Tamil Nadu, India.

\begin{abstract}
Aspergillus flavus is a fungal pathogen which infects maize crops and produces aflatoxin thus bringing about huge losses in crop production. Developing biocontrol agents against Aspergillus flavus has been the best strategy for the control of contamination in the fields. The aim of this study was to evaluate the biocontrol potential of Aspergillus giganteus against $A$. flavus by in vitro coculture studies. The effect of antagonism was studied by varying the carbon and nitrogen sources and under different interacting conditions of $\mathrm{pH}$, temperature and water activities. The conidia production by $A$. flavus during coculture conditions favourable for antagonism was also assessed. A significantly notable growth inhibition of about $86.1 \%$ was brought about by $A$. giganteus in the coculture, which surrounded the mycelia of pathogenic $A$. flavus, arresting its growth. A maximum inhibition of $86.1 \%$ was observed when sucrose was used as the carbon source and a significantly higher inhibition of $90.93 \%$ was seen when beef extract was used as the nitrogen source. Among the different temperatures tested, the highest inhibition was observed at $30^{\circ} \mathrm{C}$ which was $87.43 \%$. An increasing trend in the inhibitions were seen with decrease in $\mathrm{pH}$ and water activity $\left(\mathrm{a}^{\mathrm{w}}\right)$, where, the highest inhibition was $89.75 \%$ for $\mathrm{pH} 6.0$ and $\mathbf{9 4 . 0 3 \%}$ for $\mathrm{a}^{\mathrm{w}} \mathbf{0 . 8 4 6}$. Drastic reductions in conidial number and halting of sclerotia production was observed in coculture clearly suggesting that $A$. giganteus will serve to be a potent and promising biocontrol strain under different environmental conditions.

Keywords: Aspergillus flavus, aflatoxin, pathogenic fungi, biocontrol, Aspergillus giganteus, antagonism
\end{abstract}

*Correspondence: ramya.ek85@gmail.com; +91- 9787700505

(Received: December 02, 2019; accepted: February 15, 2020)

Citation: Ramya Krishnamurthy, Palghat Ragunathan Padma and Kavitha Dhandapani, Antagonistic Efficiency of Aspergillus giganteus as a Biocontrol Agent against Aflatoxigenic Aspergillus flavus Infecting Maize, J. Pure Appl. Microbiol., 2020; 14(1): 527-539. https://doi.org/10.22207/JPAM.14.1.55

(C) The Author(s) 2020. Open Access. This article is distributed under the terms of the Creative Commons Attribution 4.0 International License which permits unrestricted use, sharing, distribution, and reproduction in any medium, provided you give appropriate credit to the original author(s) and the source, provide a link to the Creative Commons license, and indicate if changes were made. 


\section{INTRODUCTION}

Plant diseases are caused by numerous organisms such as fungi, oomycetes, bacteria, viruses, protozoa, nematodes and so on. Among these, the most destructive and deleterious plant diseases are caused by fungal pathogens producing toxins which cause heavy losses in the crop production levels ${ }^{1}$. The most dreaded challenge is to control the mycotoxigenic fungi to tackle issues of food safety as over $25 \%$ of the global food and feed crops are affected by accumulation of mycotoxins ${ }^{2-4}$. Corn is a major staple crop which is more often affected by Aspergillus species, predominantly by $A$. flavus and A. parasiticus which contaminate the kernels by producing aflatoxins which are highly carcinogenic ${ }^{5}$. The crops are prone to contamination during the preharvest stages and storage conditions where the environmental factors play a major role ${ }^{6}$. Hence, sustainable management of infectious Aspergilli has ever since been a necessity to control aflatoxin related health issues.

To keep these diseases at bay, many fast acting chemical based fungicides are being extensively used. These strategies have not been giving favourable results in controlling soil borne pathogens due to microbial degradation of fungicides or adsorption by soil colloids ${ }^{7}$. Moreover, the use of chemical pesticides has led to various environmental problems such as ground water contamination, disturbances in natural microflora and has caused negative impact on the terrestrial and aquatic ecosystems ${ }^{8}$.

Biological control has been an effective strategy for reduction of Aspergilli contamination in maize plants ${ }^{9}$. Competition is one of the successful mechanism of action for several biocontrol agents and a better understanding of the antagonist- pathogen interaction is needed in this case ${ }^{10}$. Competition for space, infection site and nutrients between the beneficial fungi and plant pathogenic fungi occur due to colonization of the shared habitat or substrate in the environment. This character of beneficial fungi is based on its inherent ability to adapt to the plant or the environment and maintain a high population density compared to the pathogen inorder to outcompete them, forming the major bioactive principle ${ }^{11}$.
Several bacterial species such as Bacillus subtilis, Lactobacillus spp, Pseudomonas spp, Ralstonia spp and Burkholderia spp have been found to inhibit the growth of Aspergillus in laboratory experiments ${ }^{46}$. Also, fungi like Aspergillus giganteus and some marine fungi possess antifungal proteins which are capable of inhibiting the growth of several pathogenic filamentous fungi $i^{47,48}$.

The survival and activity of such biocontrol agents mainly depend on key factors such as, temperature, water availability, $\mathrm{pH}$ and the presence of heavy metal ions ${ }^{12}$. Most fungi have reduced biocontrol activity at low temperatures and hence choosing antagonists which will be effective at field temperatures is an important criteria for developing an efficient biocontrol agent ${ }^{13}$. Further, acidic $\mathrm{pH}$ conditions favour the activity of several antagonist fungi like Trichoderma and help in colonization ${ }^{14}$. Water availability is also a crucial factor in biocontrol as fungi have a high surface to volume ratio which makes them susceptible to dehydration. This in turn affects spore germination, hyphal growth and metabolite production ${ }^{15,16}$. All these abiotic factors in turn trigger complex signaling pathways and metabolisms which act synergistically.

Hence, the present study was carried out to evaluate the inhibitory capacity of the antagonistic Aspergillus giganteus against aflatoxigenic Aspergillus flavus which infects the maize plants and to test the biocontrol efficacy in various environmental conditions by in vitro assays.

\section{MATERIALS AND METHODS}

\section{Collection and maintenance of strains}

The fungal strains chosen for the study were Aspergillus flavus (MTCC 2798) and Aspergillus giganteus (MTCC 8408). Lyophilized cultures of these fungi were procured from the Microbial Type Culture Collection, Institute of Microbial Technology (IMTECH), Chandigarh. Aspergillus flavus (MTCC 2798) is an aerobic fungi, with the special feature of production of aflatoxin. The strains were maintained in Czapek Yeast Extract Agar (CYA) at $28^{\circ} \mathrm{C}$ with regular subcultures done for every 30 days. 
Co-culture in basal media to evaluate antagonism of $A$. giganteus against $A$. flavus

Competition between $A$. giganteus and $A$. flavus was assessed in Czapek Yeast Extract Agar (basal media) by co culture method as described by Weller et al. ${ }^{17}$. A mycelial agar plug of $5 \mathrm{~mm}$ diameter was obtained from the peripheral region of a 5- 7 day old culture of pathogenic $A$. flavus and placed $3 \mathrm{~cm}$ from the center in a fresh CYA plate. Likewise, a $5 \mathrm{~mm}$ mycelial plug was obtained from the peripheral region of a 5-7 day old culture of $A$. giganteus and was placed $3 \mathrm{~cm}$ away from the inoculum of the pathogen. The control plates were inoculated with a $5 \mathrm{~mm}$ mycelial plug from the culture of $A$. flavus. The plates were incubated at $28^{\circ} \mathrm{C}$ for $4-5$ days for the mycelia to grow after which the interactions were scored for degree of antagonism based on Bell's Ranking scale of classes: 1 - 5 (Bell et al. $^{18}$ ). The experiments were performed in triplicates.

Antagonism in media mimicking different environmental conditions

To evaluate the antagonistic impact of A. giganteus on the growth of $A$. flavus under different nutritional and environmental conditions, in vitro coculture experiments were conducted under different interacting conditions. This was carried out by changing the composition of basal media with variations in the carbon source, inorganic and organic nitrogen sources, under different $\mathrm{pH}$, incubation temperature and water activities.

Different carbon sources such as dextrose, maltose and lactose were used to evaluate the competition between $A$. giganteus and $A$. flavus in a coculture. The carbon sources chosen were provided at their individual $2 \%$ levels by replacing the usual carbon source -sucrose in Czapek basal media as performed in a study by Durairaj ${ }^{19}$. Similarly, cocultures were carried out where, the sodium nitrate in Czapek basal media was replaced with $3 \%$ nitrogen source of each organic nitrogen source namely peptone, beef extract and urea. The inorganic nitrogen sources used were ammonium oxalate, ammonium sulphate, and ammonium dihydrogen orthophosphate ${ }^{19}$. The control and test plates were incubated at $28^{\circ} \mathrm{C}$ for $4-5$ days after which the radial growth measurements of the mycelia were recorded. The percentage radial growth inhibition $(R)$ was calculated using the formula

$$
\mathrm{R}=\frac{\mathrm{C}-\mathrm{T}}{\mathrm{C}} \times 100
$$

where, $\mathrm{C}$ is the radial growth of $A$. flavus in control, $\mathrm{T}$ is the radial growth of $A$. flavus in co culture with $A$. giganteus (test). The experiments repeated five times for consistent inhibitions.

The responses of fungi to culture $\mathrm{pH}$ needs to be assessed in strongly buffered media as fungi tend to rapidly change the $\mathrm{pH}$ by selective uptake or exchange of ions. Therefore, cocultures of $A$. flavus with $A$. giganteus were performed, where the $\mathrm{pH}$ of Czapek basal media was adjusted to 6.0 and 8.0 from the normal pH of 7.0 in basal media ${ }^{20}$. The control and test plates were incubated at $28^{\circ} \mathrm{C}$ for $4-5$ days after which the radial growth measurements of the mycelia were recorded. The percentage inhibitions obtained were noted. Since $A$. flavus is capable of surviving at high temperatures of $35^{\circ} \mathrm{C}$ and remains dormant for long periods, cocultures were performed at different temperatures ranging from 25 to $40^{\circ} \mathrm{C}$ to test the inhibitory potential of $A$. giganteus.

By mimicking the vapour pressure conditions in field, the ability to inhibit A. flavus was also evaluated with four different water activities in Czapek media by the method of Dallyl and Fox ${ }^{21}$. The water activity of the basic medium was adjusted from 0.999 to $0.922,0.901,0.884$ and 0.846 by the addition of known amounts of nonionic solute glycerol and cocultures were performed by placing the petriplates in polythene bags at an incubation temperature of $28^{\circ} \mathrm{C}$.

The control and coculture plates for all these experiments were monitored for the radial growth measurements of the mycelia and the percentage radial growth inhibition was calculated for triplicate experiments.

\section{Preparation of spore suspension}

Spores of $A$. giganteus were prepared by growing the fungi on CYA plates for 7 days at $28^{\circ} \mathrm{C}$. The plates were flooded with sterile distilled water and $0.02 \%$ Tween 20 . The spores were dislodged with mild scraping and the number of spores were determined by using a haemocytometer ${ }^{22}$. Spore concentration of $1 \times 10^{8}$ spores $/ \mathrm{ml}$ was used as inoculum for experiments. 
Conidial quantification of $A$. flavus on solid media at culture conditions favourable for antagonism

The conidia of $A$. flavus was quantified by a method of Spraker et al. ${ }^{23}$, inorder to determine the capacity of $A$. giganteus to inhibit A. flavus spore formation in the culture conditions favourable for antagonism. Inoculums containing $10^{8}$ spores/ $\mathrm{ml}$ of $A$. flavus and $A$. giganteus were obtained from 7 day old cultures and point inoculated $3 \mathrm{~cm}$ apart in solid media containing sucrose as the carbon source, beef extract as the nitrogen source, at a $\mathrm{pH}$ of $6, \mathrm{a}^{\mathrm{w}}$ of 0.846 and incubated at $28^{\circ} \mathrm{C}$ in sealed polythene bags. The cocultures were allowed to grow for 9 days and three $1 \mathrm{~cm}$ diameter cores were punched from the centers of $A$. flavus cultures. The fungal mass and agar was homogenized and $1 \mathrm{ml}$ was removed from each sample for conidial quantification by using a haemocytometer. Two technical replicates were obtained from four separate plates and pooled. Conidia from control plates grown with axenic $A$. flavus cultures were also counted and compared in terms of fold reduction in conidia number.

Effect of $\boldsymbol{A}$. giganteus inhibition on sclerotial number of $A$. flavus

Spore suspensions of concentration $10^{5}$ spores/ $\mathrm{ml}$ of $A$. flavus and $A$. giganteus were prepared from 7 day old cultures. These were point inoculated $3 \mathrm{~cm}$ apart in solid media containing sucrose as the carbon source, beef extract as the nitrogen source, at a $\mathrm{pH}$ of 6.0 , a ${ }^{\mathrm{w}}$ of 0.846 and incubated at $28^{\circ} \mathrm{C}$ for 15 days. Plates were maintained in polythene bags to maintain water activity. Sclerotia were obtained adopting a method described by Nesci et al. ${ }^{24}$, by scraping the surface of the culture plate over a whatman four sieve during irrigation with water containing Triton- X 100 (0.1\%) followed by rinsing in sterile water. Sclerotia were further cleaned in a beaker with repeated rinses and decanting, air dried and stored in a dessicator. Sclerotium shape was approximated to be prolate spheroid and the number of sclerotia were counted on each replicate plate.

\section{Statistical Analysis}

All the experiments were performed in triplicates and the values are represented as mean \pm standard error. The significance of the tests were analysed with $t$ - test at a level of $p \leq 0.05$ with SPSS software (21.0)

\section{RESULTS AND DISCUSSION}

Antagonistic potential of $A$. giganteus in coculture against $A$. flavus

In the coculture assay, the growth of $A$. flavus was arrested by the overgrowth of $A$. giganteus which surrounded the $A$. flavus mycelia. According to Bell's ranking scale, the interaction is said to be class 1- if there is complete overgrowth of the pathogen by the antagonist, class 2- for $75 \%$ overgrowth of antagonist, class 3 - for $50 \%$ overgrowth of antagonist, class 4- for growth inhibition at the line of contact and class 5- for pathogen overgrowing the antagonist. In the present study, the antagonism can be ranked as class 1 , as there was complete overgrowth of A. giganteus over $A$. flavus with competition for space and nutrients (Fig. 1).

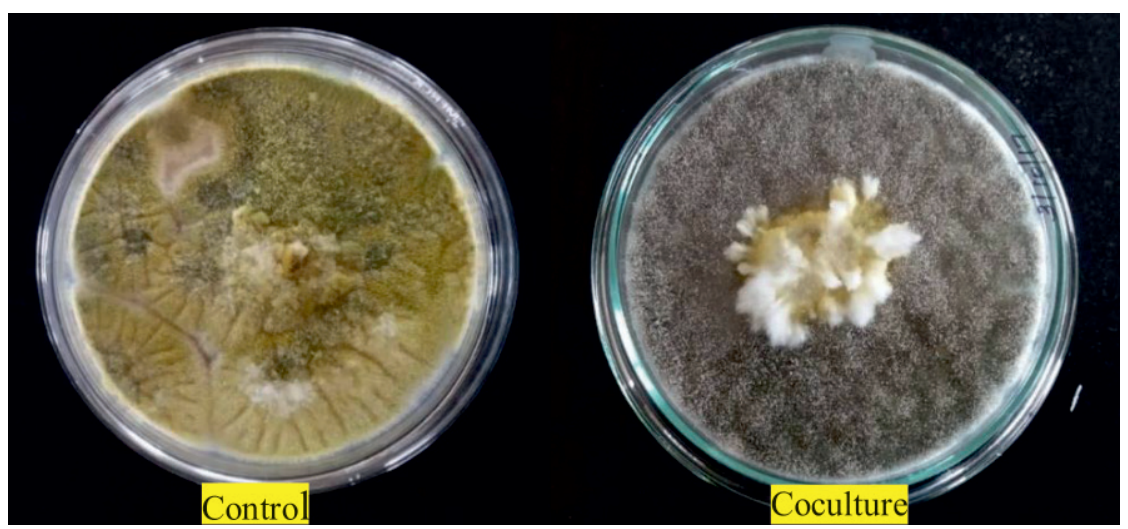

Fig. 1. Control plate shows axenic culture of $A$. flavus whereas in coculture, mycelial growth of pathogenic $A$. flavus is surrounded by the mycelia of $A$. giganteus. The interaction between the fungi was ranked as Class 1 based on Bell's Ranking scale as $A$. giganteus showed massive overgrowth over the pathogen. 
A significantly higher percentage of growth inhibition of $86.1 \%$ was observed in coculture plates. Further, the peripheral region between the fungi showed no intermingling of the hyphae suggesting that the antagonism was due to competition for space and nutrients (Fig. 2).

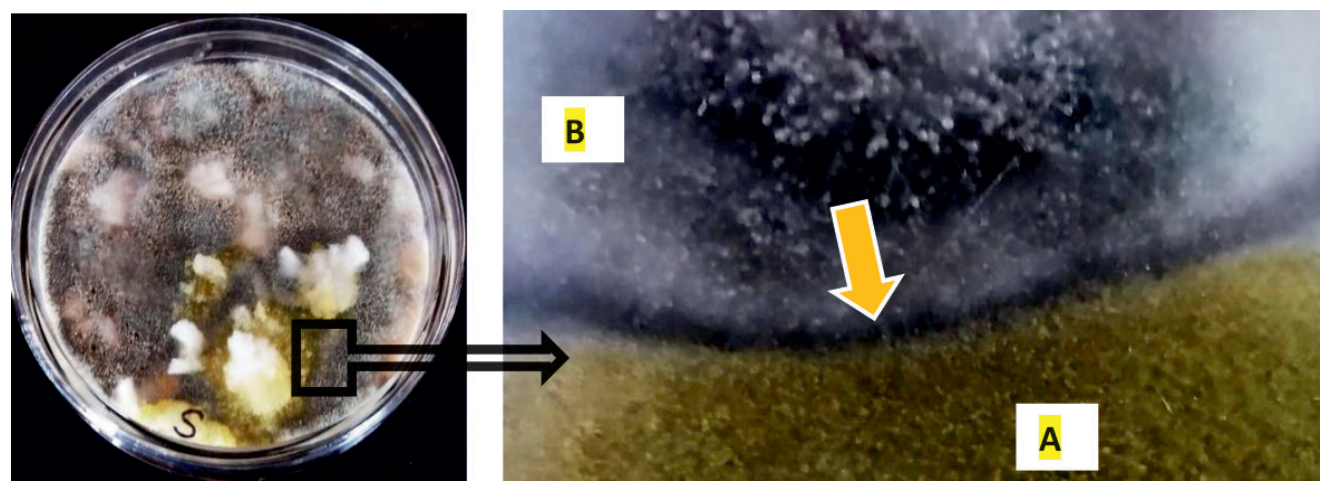

Fig. 2. Mycelial interaction between the pathogenic $A$. flavus (A) and A. giganteus (B) showed no intermingling of hyphae in the region between the two hyphae at the periphery as indicated (enlarged view)

A similar study conducted by Madbouly et al. ${ }^{25}$ using bioassays such as dual culture proved that Penicillium crustosum, Aspergillus giganteus, Fusarium verticillioides and Aspergillus fumigatus isolates had promising antifungal activities against pathogenic fungi. This was due to the rapid growth of the antagonists competing for space and nutrients with the pathogenic fungi ${ }^{26}$. Kucuk and $\mathrm{Kyvanc}^{27}$, studied the in vitro interactions and established the antagonistic activity of several fungi from maize rhizosphere. The study involved several species of Aspergillus, Penicillium, Fusarium and Trichoderma, of which Aspergillus ustus, $A$. versicolor and Gliocladium viride were able to dominate all the fungi tested due to their rapid and invasive growth characteristic.

Antagonistic effect of $\boldsymbol{A}$. giganteus in media mimicking different environmental conditions

There is a lag in the commercial use and application of biological control agents as the environmental conditions cause an impact in their performances in the field. Hence better understanding of the interactions between biological interactions and environmental factors such as substrate, temperature and water activity is a must to develop effective biocontrol strategies ${ }^{28}$. Some metabolites produced by the biocontrol agents interfere with the pathogen growth but the effectiveness of these metabolites also depends on the carbon and nitrogen composition in the environment ${ }^{29}$.

\section{Growth inhibition in different carbon sources}

Among the inhibitions seen for different carbon sources, the percentage inhibition by $A$. giganteus was found to be higher with $86.1 \%$ (Fig. 3, Fig.4), when sucrose was used as the carbon source. But the differences in inhibition levels were not very significant among the different carbon sources tested, and therefore proves that A. giganteus has significant inhibitory capacity of over $85 \%$ even when the carbon sources vary in the environment.

Simple sugars such as sucrose and glucose are associated with promoting high fungal growth and sporulation ${ }^{30}$. Hence, evaluation of antagonism in different carbon sources is one of the primary steps in biocontrol development. Daryaei et al. ${ }^{31}$, performed a study by manipulating the culture conditions and nutritional requirements in a coculture assay to test the bioactivity of Trichoderma atroviride against Rhizoctonia solani, to help in optimum production of biocontrol agents. Similar binary competition assays on different carbon sources were done by Bodmer et al. ${ }^{32}$, in which Candida subhashii was identified as an effective antagonist exhibiting about $80 \%$ inhibition against filamentous plant pathogenic fungi. It is known that the antagonism of several fungi depend on the different mechanisms which include right from the production of antifungal metabolites to the competition for space and nutrients $^{33}$. Hence it can be said that $A$. giganteus 


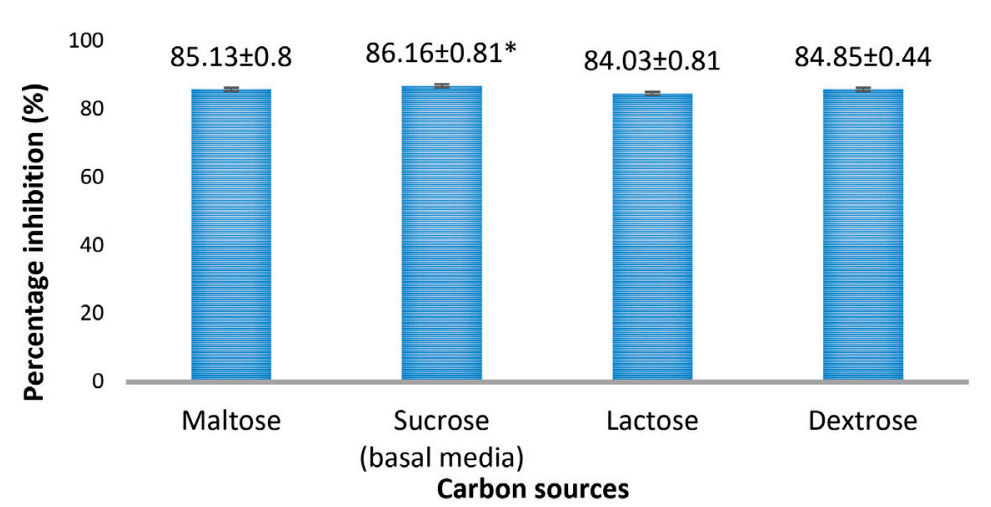

Fig. 3. Percentage inhibition of $A$. flavus growth in different carbon sources showing highest inhibition with sucrose as carbon source. Inhibition percentage $=$ (Control- Test/ Control) $\times 100$. Values are represented as Mean $\pm S D(n=5)$. *Value is statistically significant for $\mathrm{P} \leq 0.05$ in t-test.

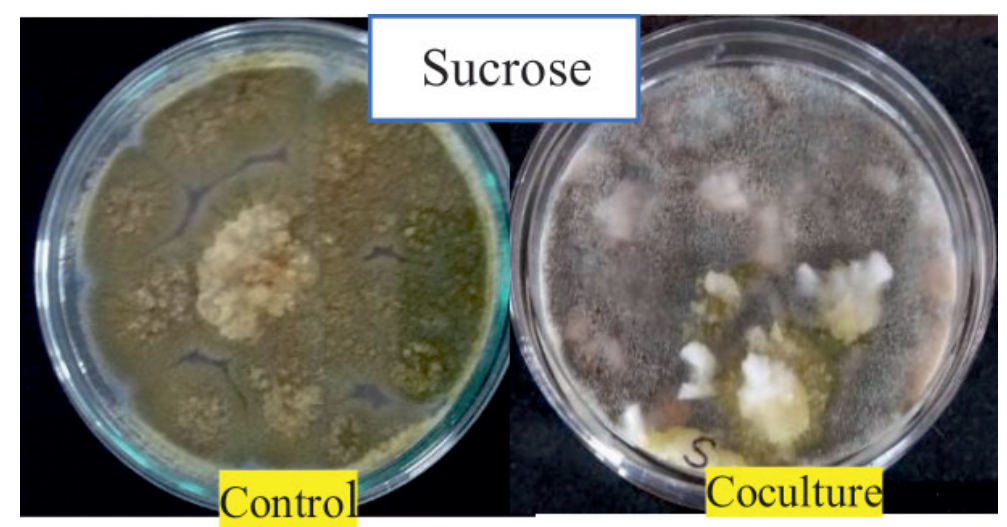

Fig. 4. Antagonistic effect of $A$. giganteus on pathogenic $A$. flavus during coculture in media with sucrose as carbon source

is capable of antagonizing the pathogenic $A$. flavus by competing for nutrients and space.

Effect of different organic and inorganic nitrogen sources on the inhibition of $A$. flavus

From Fig. 5 and 7, it can be seen that the highest percentage of inhibition was $90.3 \%$ when beef extract was used as nitrogen source. This inhibition was significantly higher than that obtained for sodium nitrate (86.1\%), which was used in basal media. Also this did not vary much from the inhibitions obtained when different inorganic nitrogen sources were used (Fig. 6). Nitrogen sources play a role in the formation of developmental structures such as sclerotia in Aspergillus flavus. Further, studies have proved that nitrate forms of nitrogen source encourage sclerotia production ${ }^{34}$. The results obtained in this study imply that $A$. giganteus is capable of utilizing both forms of nitrogen and exhibit a significantly good antagonistic effect against pathogenic $A$. flavus though the highest inhibition was seen with beef extract.

A study by Daryaei et al. ${ }^{35}$, showed that culture conditions and nutritional requirements in a coculture assay affect the biocontrol nature of Trichoderma atroviride against Rhizoctonia solani while infecting ryegrass. The in vitro antagonism of Trichoderma harzianum against Mycosphaerella fijiensis also used a mechanism of competition for space and nutrients where, invasion of the surface of the colony and colonization predominated ${ }^{36}$. Competition for nutrients could lead to higher production of metabolites responsible for antagonism as it is considered as a stress factor by the antagonist fungi. This is due to the competition between the different forms of nitrogen such as the ammonium and nitrate forms between the phytopathogenic and antagonistic 
fung $\mathrm{i}^{37}$. Further, $A$. giganteus is already known to produce certain basic, cysteine rich antifungal proteins (AFPs) which have been used effectively against pathogens such as Magnaporthe grisea; and these AFPs might also be attributed to be responsible for the inhibitory effect against $A$. flavus in this study ${ }^{47}$.

Influence of $\mathrm{pH}$ on the inhibition of $A$. flavus in co culture

The percentage inhibitions increased with decrease in $\mathrm{pH}$, with a maximum inhibition of $89.75 \%$ observed at pH 6.0 (Fig.8 and 9). This was found to be higher when compared to the inhibition obtained when $\mathrm{pH}$ was 7.0 in basal media (86.1\%). This indicates that $A$. giganteus has the ability to adapt to $\mathrm{pH}$ variations which will help to combat $A$. flavus in the field. Further the soil $\mathrm{pH}$ for maize growing conditions is around 6.0 to 7.0 . Hence, $A$. giganteus will be efficient in inhibiting the growth of pathogenic $A$. flavus in the environmental $\mathrm{pH}$ conditions which favour maize growth.

A similar study was conducted in Candida parapsilosis by Niknejad et al. ${ }^{38}$, which showed significant reductions in mycelial growth of Aspergillus isolates at a range of $\mathrm{pH}$ variations. In a study by Armando et al. ${ }^{39}$, growth inhibition of Aspergillus parasiticus by Saccharomyces cerevisiae strains at various environmental conditions was observed for proving it to be an effective biocontrol agent.

Inhibition of $A$. flavus at different temperatures

The percentage inhibition of $A$. flavus by $A$. giganteus was significant with $87.43 \%$ at

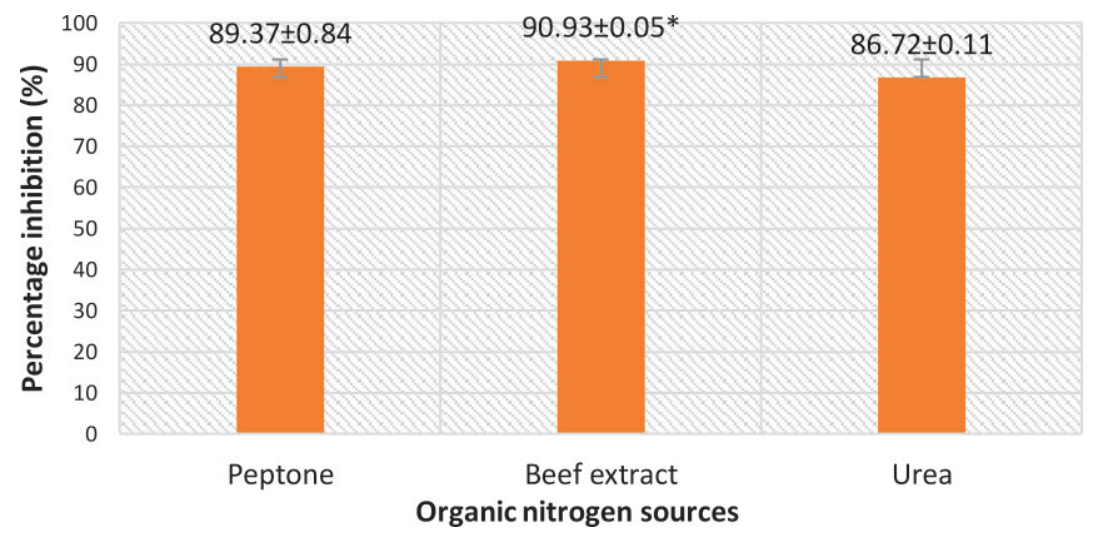

Fig 5. Percentage inhibition of $A$. flavus growth in different organic nitrogen sources with maximum inhibition obtained for Beef extract. Inhibition percentage $=$ (Control- Test/ Control) $\times 100$. Values are represented as Mean $\pm \mathrm{SD}(\mathrm{n}=3) .{ }^{*}$ Value is statistically significant at $\mathrm{P} \leq 0.05$ in t- test

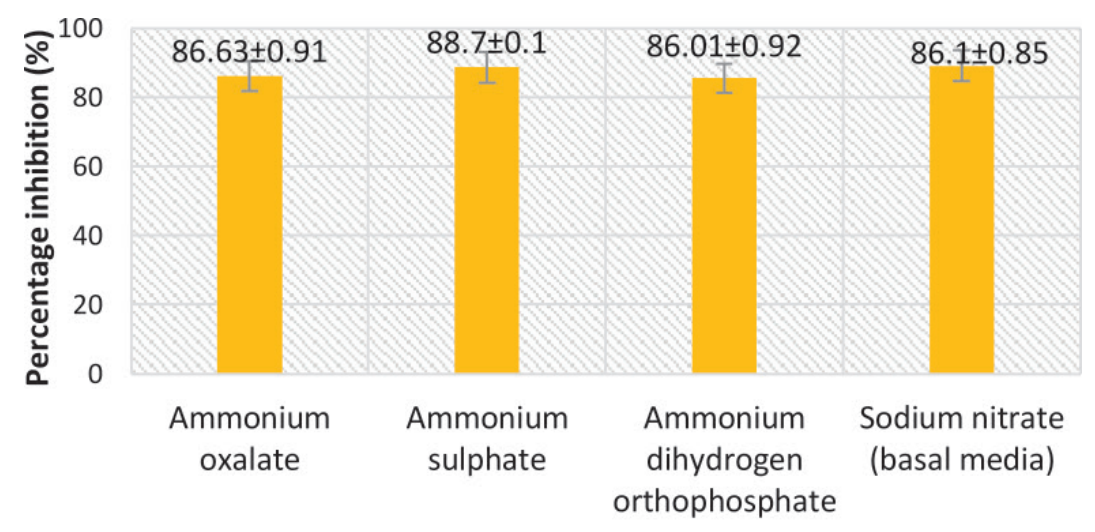

Inorganic nitrogen sources

Fig. 6. Percentage inhibition of $A$. flavus growth in different inorganic nitrogen sources where the inhibitions are significantly less compared to those obtained for beef extract. Inhibition percentage $=$ (Control- Test $/$ Control) $\times 100$. Values are represented as Mean $\pm \operatorname{SD}(n=3)$ 

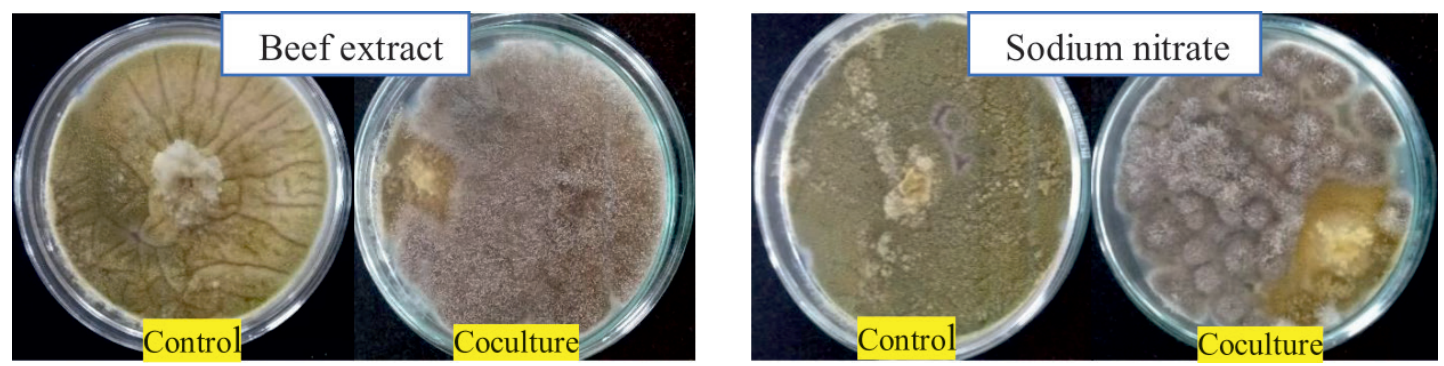

Fig. 7. Overgrowth of $A$. giganteus over pathogenic $A$. flavus during coculture in media with Beef extract as organic nitrogen source and sodium nitrate as inorganic nitrogen source

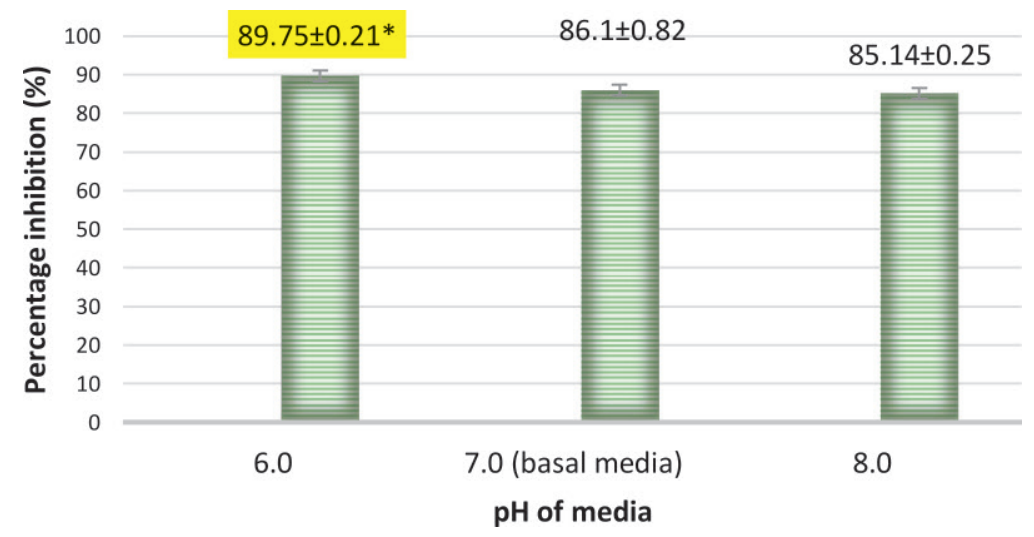

Fig. 8. Percentage inhibition of $A$. flavus growth at different $\mathrm{pH}$ on coculture with $A$. giganteus showing an increasing trend in inhibition as the $\mathrm{pH}$ decreased. Inhibition percentage $=$ (ControlTest/ Control) $\times 100$. Values are represented as Mean $\pm S D(n=3)$. *Value is statistically significant at $P \leq 0.05$ compared to normal $\mathrm{pH} 7.0$

$30^{\circ} \mathrm{C}$ (Fig. 10 and 11) which is the predominant field temperature for maize growing regions. Though the inhibition at normal incubation temperature $28^{\circ} \mathrm{C}$ was about $86.1 \%$, $A$. giganteus could also show an inhibition of $75.92 \%$ at higher temperatures of around $40^{\circ} \mathrm{C}$ suggesting that the organism will be capable of effectively controlling the pathogenic fungi thus confirming the ability of $A$. giganteus to combat $A$. flavus at extreme temperatures in the field.

A similar study by Niknejad et al. ${ }^{38}$

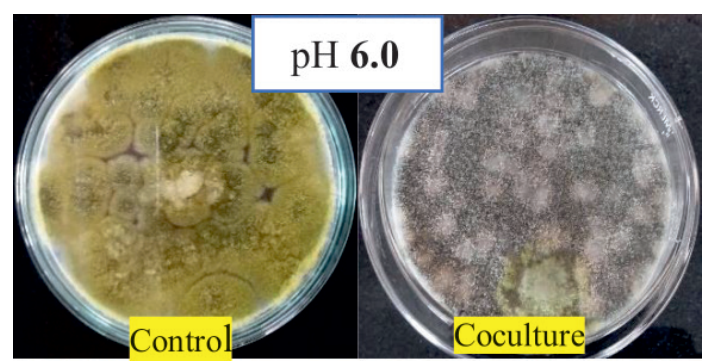

Fig. 9. Maximum antagonism of $A$. giganteus against pathogenic $A$. flavus (89.75\%) at pH 6.0 showing arrested growth of pathogenic fungi showed significant reductions in mycelial growth of Aspergillus isolates at a range of temperatures when cocultured with Candida parapsilosis having the other growth conditions optimised. In a study by Armando et al. ${ }^{40}$, complete growth inhibition of Fusarium graminearum by Saccharomyces cerevisiae RC016 at a temperature range of $25-37^{\circ} \mathrm{C}$ was observed, considering it to be an effective biocontrol agent at different interacting environmental conditions.

Effect of various water activities on the inhibition of $A$. flavus in co culture

The percentage inhibition was found to increase gradually from 86.37 to $94.03 \%$ with decrease in water activity (Fig. 12 and 13). This suggests that as water activity decreases in the environment, $A$. giganteus growth is much aggressive with the capacity to inhibit $A$. flavus efficiently. This kind of tolerance to a range of water activity could provide high survival rates of the antagonist fungi when used in the fields, thus providing the capacity to compete and exclude 


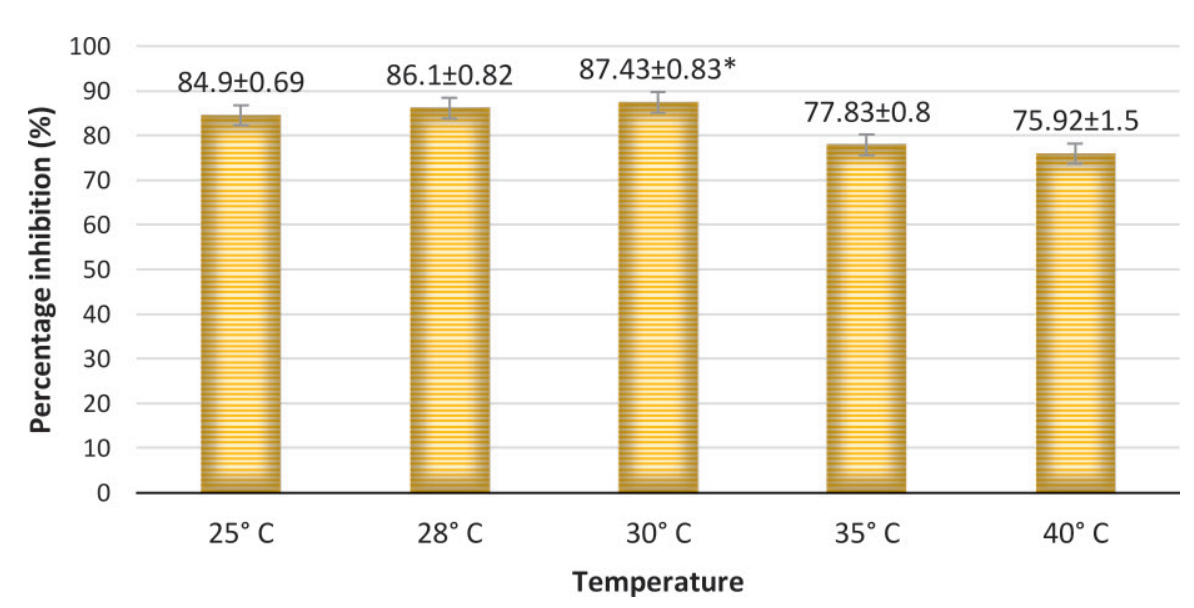

Fig. 10. Percentage inhibition of $A$. flavus at different temperatures where maximum inhibition was observed at a temperature of $30^{\circ} \mathrm{C}$. Inhibition percentage $=($ Radius of Control- Radius of Test $/$ Radius of Control) $\times 100$. Values are represented as Mean $\pm S D(n=3)$. *Value is statistically significant at $P \leq 0.05$ in t- test

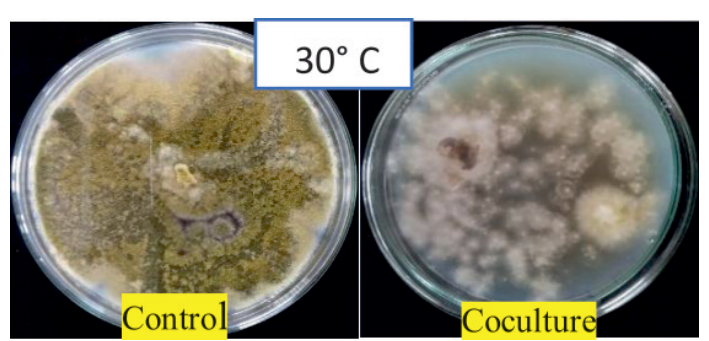

Fig. 11. Highest antagonism of $A$. giganteus observed at an incubation temperature of $30^{\circ} \mathrm{C}$ showing stunted growth of pathogenic $A$. flavus

toxigenic fungi from the ecological niche.

In vitro assays done by Etcheverry et al. ${ }^{41}$ have shown similar inhibitions by $M$. oleovorans, B. amyloliquefaciens and Kluyveromyces sp L16

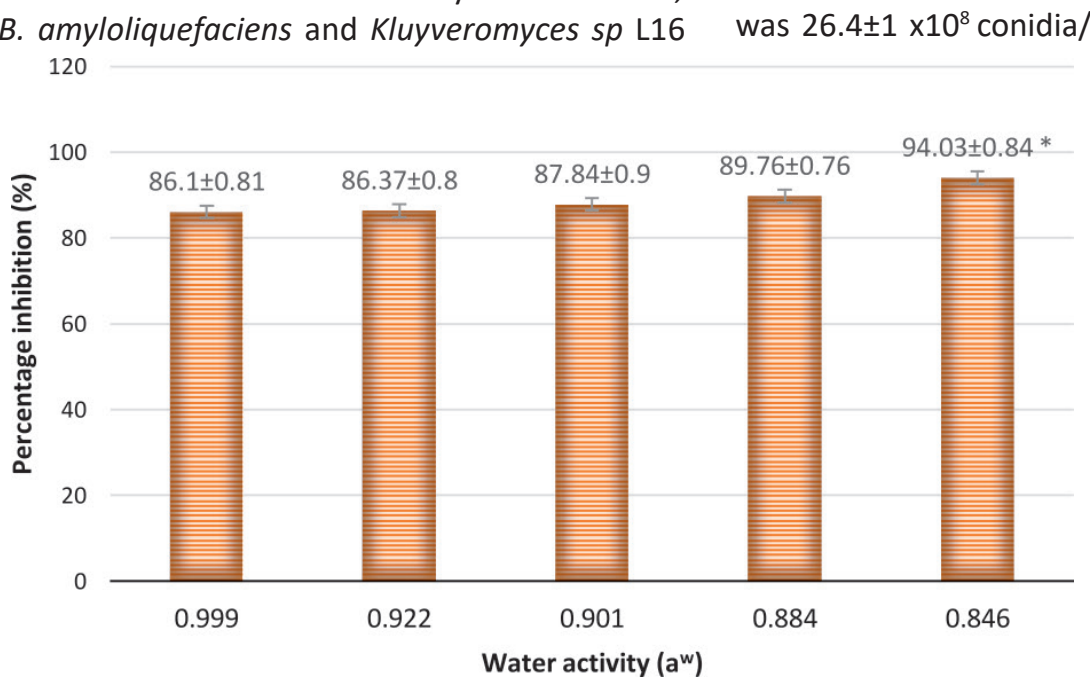

Fig. 12. Percentage inhibition of $A$. flavus at different water activities showing an increasing trend in inhibitions as water activity decreased. Inhibition percentage $=$ (Radius of Control- Radius of Test/ Radius of Control) $\times 100$. Values are represented as Mean $\pm S D(n=3)$. *Value is statistically significant at $P \leq 0.05$ in t-test

acting as potent biocontrol strains against several Fusarium and Aspergillus strains. In another study by Nesci et al. ${ }^{24}$, microbes such as Amphibacillus xylanus, Bacillus subtilis and Sporolactobacillus inulinus were able to inhibit the Aspergillus growth. This fact is also supported by a study by LaPenna and coworkers ${ }^{42}$, where the impact on the growth of Aspergillus flavus isolates at different water activities were observed when cocultured with Kluyveromyces species.

Conidial quantification under culture conditions favourable for antagonism

The conidia in coculture plates accounted to about $0.62 \pm 0.1 \times 10^{8}$ conidia $/ \mathrm{ml}$ whereas it was $26.4 \pm 1 \times 10^{8}$ conidia $/ \mathrm{ml}$ in control. Thus the 


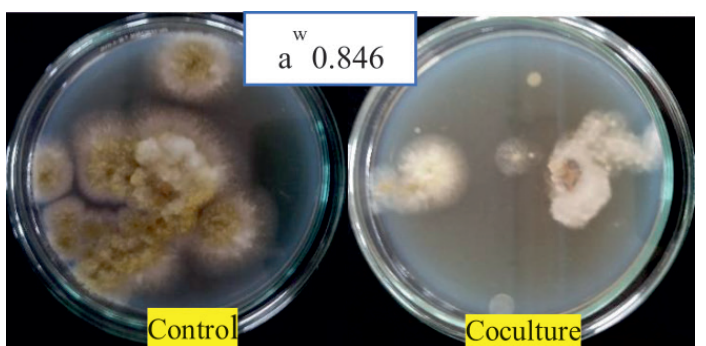

Fig. 13. Maximum antagonism of $A$. giganteus observed against pathogenic $A$. flavus at water activity of 0.846 where mycelia formation was stunted coculture plates had a highly significant reduction (at $\mathrm{P} \leq 0.01$ confidence level) in conidial number by 42 fold when compared to the axenic Aspergillus flavus plates. This suggests that the sporulation process of Aspergillus flavus is inhibited by the antagonist Aspergillus giganteus which is a much required criteria for a potential biocontrol effect. Spraker et al. ${ }^{23}$, studied the effect of volatiles of Ralstonia solanacearum against the aflatoxigenic Aspergillus flavus which were effective in reducing the conidiation of the latter. The conidiation and the fungal growth are said to be associated factors in the metabolism of fungi and hence simultaneous reductions in conidia support reductions in mycelial growth ${ }^{43}$.

Impact of A.giganteus on sclerotia production of $A$. flavus

Sclerotia are compact mass of hardened mycelium which survive under stressed conditions, thus giving the ability to the fungi to recoup in favourable conditions. In this study, the number of sclerotia in control plates were found to be $435 \pm 7$ whereas those found in the coculture plates were $6 \pm 1$ (Fig. 14). Thus, a significantly drastic reduction in the number of sclerotia was witnessed during the coculture which implies that the pathogen will not be allowed to form any sclerotia in the field conditions due to inhibition by $A$. giganteus. Also, the secondary metabolism of pathogenic fungi and the sclerotia formation is interlinked because they are triggered by a common gene cluster ${ }^{44,45}$. Therefore inhibition of sclerotia production will definitely have an impact on the secondary metabolite production in the pathogenic fungi which is an advantage in biocontrol.
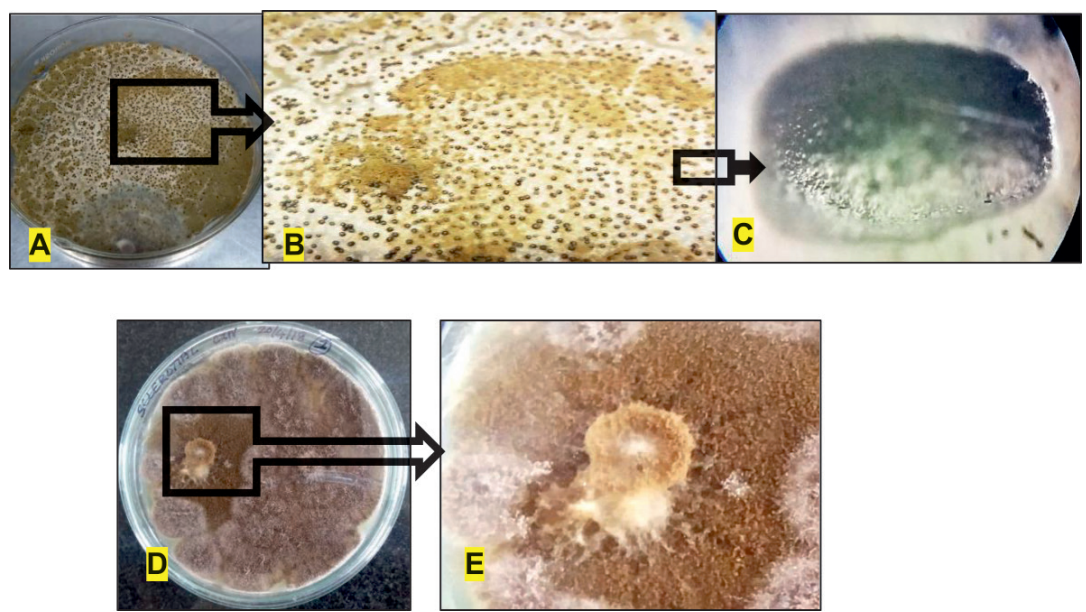

Fig. 14. Impact of $A$. giganteus on sclerotia production of $A$. flavus: A- Control petriplate showing growth of $A$. flavus with abundant sclerotia, B-Closer view of sclerotia in control plate, C- Zoomed picture of a single prolate spheroid sclerotia as viewed in a light microscope under 100Xmagnification, D- Coculture petriplate showing the reduced growth of $A$. flavus, E- Closer view of coculture plate showing no visible sclerotia formation.

\section{CONCLUSION}

The present study gives us a better understanding of the antagonistic behavior of Aspergillus giganteus providing a lead for the development of a successful biocontrol agent against aflatoxigenic Aspergillus flavus. Though the environmental conditions were mimicked in vitro, the inhibitory activity of $A$. giganteus was remarkable implying that this strain will perform better in future field trials under extreme stress conditions. The inhibition of sporulation process of $A$. flavus by the culture filtrates of $A$. giganteus is an added advantage for field application as the compounds responsible for inhibition can be 
assessed and used instead of releasing the whole strain for biocontrol. Thus with further focus on the application strategies, $A$. giganteus can be developed into a potent bicontrol agent against aflatoxigenic $A$. flavus to save maize crops.

\section{ACKNOWLEDGEMENTS}

The authors wish to acknowledge IMTECH, Chandigarh for providing the pure fungal strains to carry out this research and the CNR Rao Research Centre of Avinashilingam Institute for Home Science and Higher education for Women, Coimbatore, India.

\section{CONFLICT OF INTEREST}

The authors declare that there is no conflict of interest.

\section{FUNDING}

None.

\section{AUTHORS' CONTRIBUTIONS}

RK and KD laid the work plan for the experiments. PRP and KD supervised the work and results. Experimental work, interpretation of results and manuscript preparation was carried out by R K.

\section{DATA AVAILABILITY}

All the data analysed during the course of this study are included in the manuscript.

\section{ETHICS STATEMENT}

This study did not involve any human subjects or animals.

\section{REFERENCES}

1. Van Alfen NK. Fungal pathogens of plants. Wiley InterScience: Chichester, 2001. https://doi. org/10.1038/npg.els.0000362

2. FAO. Mycotoxin Regulations in 2003 and Current Developments, 2003. Retrieved on May 14, 2019 from http://www.fao. org/docrep/007/y5499e/y5499e07. htm.

3. FAO. Staple Foods: what Do People Eat?, 2017. Retrieved on May 14, 2019.

4. Sarrocco S. Dung-inhabiting fungi: a potential reservoir of novel secondary metabolites for the control of plant pathogens. Pest Manag. Sci. 2016; 72(4): 643-652. https://doi.org/10.1002/ps.4206

5. Ostry V, Malir F, Toman J, Grosse Y. Mycotoxins as human carcinogens- The IARC Monographs classification. Mycotoxin Res., 2017; 33(1): 65-73. https://doi.org/10.1007/s12550-016-0265-7

6. Bryden WL. Mycotoxin contamination of the feed supply chain: implications for animal productivity and feed security. Anim. Feed Sc. Technol., 2012; 173: 134158. https://doi.org/10.1016/j.anifeedsci.2011.12.014

7. Cadkova E, Komarek M, Kaliszova R, Vanek A, Balikova M. Tebuconazole sorption in contrasting soil types. Soil Sed. Contam., 2013; 22: 404-414. https://doi.org/10 $.1080 / 15320383.2013 .733448$

8. Tilman D, Cassman KG, Matson PA, Naylor R, Polasky S. Agricultural sustainability and intensive production practices. Nature, 2002; 418: 671-677. https://doi. org/10.1038/nature01014

9. Atehnkeng J, Ojiambo PS, Cotty PJ, Bandyopadhyay R. Field efficacy of a mixture of atoxigenic Aspergillus flavus vegetative compatibility groups in preventing aflatoxin contamination in maize (Zea mays L.). Biol. Contr. 2014; 72: 62-70. https://doi.org/10.1016/j. biocontrol.2014.02.009

10. Jensen DF, Karlsson M, Sarrocco S, Vannacci G. Biological control using microorganisms as an alternative to disease resistance. In: Collinge, D.B. (Ed.), Biotechnology for Plant Disease Control, 2016; 341-363. Wiley: New York and London. https://doi. org/10.1002/9781118867716.ch18

11. Ghorbanpour M, Omidvari M, Abbaszadeh- Dahaji P, Omidvari R, Kariman K. Mechanisms underlying the protective effects of beneficial fungi against plant diseases. Biological Control, 2018; 117: 147-157. https://doi.org/10.1016/j.biocontrol.2017.11.006

12. Kredics L, Antal Z, Manczinger L, Szekeres A, Kevei $F$, Nagy E. Influence of environmental parameters on Trichoderma strains with biocontrol potential. Food Technol. Biotechnol., 2003; 41: 37-42. UDC 582.282:579.264:579.61:616-092 review.

13. Domingues MVPF, de Moura KE, Salamao D, Elias LM, Patricio FRA. Effect of temperature on mycelial growth of Trichoderma, Sclerotinia minor and $S$. sclerotiorum, as well as on mycoparasitism. Summa Phytopathologica, 2016; 44(3): 222-227. https://doi. org/10.1590/0100-5405/2146

14. Pelagio-flores R, Esparza- Reynoso S, Garnica- Vergara A, Lopez- bucio J, Herrera- Estrella A. Trichoderma induced acidification is an early trigger for changes in Arabidopsis root growth and determines fungal phytostimulation. Front Plant Sci., 2017; 8: 822. https://doi.org/10.3389/fpls.2017.00822

15. Magan N. Effects of water potential and temperature on spore germination and germ-tube growth in vitro and on straw leaf sheaths. Trans. Br. Mycol. Soc., 1988; 90: 97-107. https://doi.org/10.1016/S0007$1536(88) 80185-2$

16. Lupo S, Dupont J, Bettucci L. Ecophysiology and saprophytic ability of Trichoderma spp. Cryptogam. Mycology, 2002; 23: 71-80. agris.fao.org

17. Weller DM, Zhang BX, Cook RJ. Application of a rapid screening test for selection of bacteria suppressive to take-all of wheat. Plant Dis., 1985; 69: 710-713. agris. fao.org.

18. Bell DK, Wells HD, Markham CR. In vitro antagonism of Trichoderma spp against six fungal plant pathogens. Phytopathology, 1982; 72: 379-382. https://doi. 


\section{org/10.1094/Phyto-72-379}

19. Durairaj V. Growth of Colletotrichum capsici in pure culture. J. Indian Bot. Soc., 1956; 35: 409-414.

20. Singh DB. Effect of Culture Media, $\mathrm{pH}$ and Temperature on Growth Behaviour of Alternaria brassicae and Drechslera graminea: Proceedings of the Indian National Science Academy. Part B. Biological Sciences, 1980; 46(3): 393-396.

21. Dallyn $\mathrm{H}$, Fox A. Spoilage of material of reduced water activity by xerophilic fungi. In: Gould GH, Corry EL, editors, 1980; 129-139. Society of applied bacteriology technical series 15. London, UK: Academic Press.

22. Thanaboripat D, Sappakitjanon N, Prommi L, Chareonsettasilp, S. Screening of Fungi for the Control of Aspergillus parasiticus. KMITL Science and Technology Journal, 2009; 9(2): 95-102. https://www. tci-thaijo.org/index.php/cast/article/view/137211

23. Spraker JE, Jewell K, Roze LV, Scherf J, Ndagano D, Beaudry R, Linz JE, Allen C, Keller NP. A Volatile Relationship: Profiling an Inter-Kingdom Dialogue Between two Plant Pathogens, Ralstonia Solanacearum and Aspergillus flavus. J Chem Ecol., 2014; 40: 502-513. https://doi.org/10.1007/s10886-014-0432-2

24. Nesci A, Bluma R, Etcheverry M. In vitro selection of maize rhizobacteria to study potential biological control of Aspergillus section Flavi. Eur J Plant Pathol., 2005; 113(2): 1-13. https://doi.org/10.1007/s10658005-5548-3

25. Madbouly AK, Ibrahim MIM, Abdel-Wahhab MA. Efficacy of corn and rice seed-borne mycoflora in controlling aflatoxigenic Aspergillus flavus, Comunicata Scientiae.2014; 5(2): 118-130. DOI: https://doi. org/10.14295/cs.v5i2.284.

26. Barbosa MA, Rehn GK, Menezes M, Mariano LR. Antagonism of Trichoderma species on Cladosporium herbarum and their enzymatic characterization. Brazilian Journal of Microbiology, 2001; 32: 98-104. https://doi.org/10.1590/S1517-83822001000200005

27. Kucuk C, Kyvanc M. In vitro interactions and fungal populations isolated from maize rhizosphere. Journal of Biological Sciences, 2011; 11(8): 492-495. https:// doi.org/10.3923/jbs.2011.492.495

28. Lacey J, Magan N. Fungi in cereal grains: their occurrence and water and temperature relationships. In: Chelkowski J, editor. Cereal grain, mycotoxins, fungi and quality in drying and storage. Developments in Food Science. Elsevier: Amsterdam, 1991. http://agris. fao.org/agris-search/search.do?recordID=NL9203842.

29. Bull CT, Shetty KG, Subbarao KV. Interactions between Myxobacteria, plant pathogenic fungi and biocontrol agents. Plant Dis., 2002; 86: 889-896. https://doi.org/10.1094/PDIS.2002.86.8.889

30. Buchanan RL, Stahl HG. Ability of various carbon sources to induce and support aflatoxin biosynthesis by Aspergillus parasiticus. J. Food Safety, 1984; 6: 271-279. https://doi.org/10.1111/j.1745-4565.1984. tb00488.x

31. Daryaei A, Jones EE, Glare TR, Falloon RE. pH and water activity in culture media affect biological control activity of Trichoderma atroviride against Rhizoctonia solani. Biological Control, 2016; 92: 24-30. https://doi. org/10.1016/j.biocontrol.2015.09.001
32. Bodmer $\mathrm{MH}$, Schmid $\mathrm{M}$, Ahrens $\mathrm{CH}$, Freimoser FM. Competition assays and physiological experiments of soil and phyllosphere yeasts identify Candida subhashii as a novel antagonist of filamentous fungi. $B M C$ Microbiology, 2017; 17: 4. https://doi.org/10.1186/ s12866-016-0908-z

33. Howell CR. Mechanisms employed by Trichoderma species in the biological control of plant diseases: the history and evolution of current concepts. Plant Dis., 2003; 87: 4- 10. https://doi.org/10.1094/ PDIS.2003.87.1.4

34. Bennett JW, Rubin PL, Lee LS, Chen PN. Influence of trace elements and nitrogen source on versicolorin production by a mutant strain of Aspergillus parasiticus. Mycopathologia, 1979; 69: 161-166. https://doi.org/10.1007/BF00452829

35. Daryaei A, Jones E, Ghazalibiglar H, Glare T, Falloon R. Culturing conditions affect biological control activity of Trichoderma atroviride against Rhizoctonia solani in ryegrass. J Appl Microbiol., 2016; 121: 461-472. https://doi.org/10.1111/jam.13163

36. Suarez M A, Pichardo T, Roque B, Cruz-Martin M, Mena E, Leiva-Mora M, Castro R, Capo Y A. Antagonismo in vitro de Trichoderma harzianum Rifai contra Mycosphaerella fijiensis Morelet. Biotecnologia Vegetal., 2013; 13(4): 231-23. https://revista.ibp. co.cu/index.php/BV/article/view/124.

37. Celar F. Competition for ammonium and nitrate forms of nitrogen between some phytopathogenic and antagonistic soil fungi. Biological Control, 2003; 28: 1924. https://doi.org/10.1016/S1049-9644(03)00049-5

38. Niknejad F, Zaini F, Faramarzi MA, Amini M, Kordbacheh P, Mahmoudi M, Safara M. Candida parapsilosis as a Potent Biocontrol Agent against Growth and Aflatoxin Production by Aspergillus Species. Iranian J Publ Health., 2012; 41(10): 72-80. PMID: 23308351.

39. Armando MR, Dogi CA, Rosa CAR, Dalcero AM, Cavaglieri LR. Saccharomyces cerevisiae strains and the reduction of Aspergillus parasiticus growth and aflatoxin B1 production at different interacting environmental conditions, in vitro. Food Additives and Contaminants, 2012; 29: 1443-1449. https://doi.org/ 10.1080/19440049.2012.698655

40. Armando MR, Dogi CA, Poloni V, Rosa CAR, Dalcero AM, Cavaglieri LR. In vitro study on the effect of Saccharomyces cerevisiae strains on growth and mycotoxin production by Aspergillus carbonarius and Fusarium graminearum. International Journal of Food Microbiology, 2013; 161: 182-188. https://doi. org/10.1016/j.ijfoodmicro.2012.11.016

41. Etcheverry MG, Scandolara A, Nesci A, Vilas Boas Ribeiro MS, Pereira P, Battilani P. Biological Interactions to Select Biocontrol Agents against Toxigenic Strains of Aspergillus flavus and Fusarium verticillioides from Maize. Mycopathologia, 2009; 167: 287-295. https:// doi.org/10.1007/s11046-008-9177-1

42. La Penna M, Nesci A, Etcheverry M. In vitro studies on the potential for biological control on Aspergillus section Flavi by Kluyveromyces species. Letters in Applied Microbiology, 2004; 38(4): 257-264. https:// doi.org/10.1111/j.1472-765X.2003.01467.x

43. De Lucca J, Carter-Wientjes C H, Boue S, Bhatnagar D. 
Volatile trans-2-hexenal, a soybean aldehyde, inhibits Aspergillus flavus growth and aflatoxin production in corn. J Food Sci., 2011; 76: 381- M386. https://doi. org/10.1111/j.1750-3841.2011.02250.x

44. Amare MG, Keller NP. Molecular mechanisms of Aspergillus flavus secondary metabolism and development. Fungal Genet Biol., 2014; 66: 11-18. https://doi.org/10.1016/j.fgb.2014.02.008

45. Grintzalis K, Vernardis SI, Klapa MI, Georgiou CD. Role of oxidative stress in Sclerotial Differentiation and Aflatoxin B1 Biosynthesis in Aspergillus flavus. Applied and Environmental Microbiology, 2014; 80(18): 55615571. https://doi.org/10.1128/AEM.01282-14

46. Mwakinyali SE, Ding X, Ming Z, Tong W, Zhang Q, Li P. Recent development of Aflatoxin contamination
Biocontrol in agricultural products. Biological Control, 2019; 31-39. https://doi.org/10.1016/j. biocontrol.2018.09.012

47. Barakat $H$, Spielvogel A, Hassan M, El-Desouky A, El-Mansy H, Rath F, Meyer V, Stahl U. The antifungal protein AFP from Aspergillus giganteus prevents secondary growth of different Fusarium species on barley. Applied Microbiology and Biotechnology. 2010; 87: 617-624. https://doi.org/10.1007/s00253-0102508-4

48. Kong Q. Marine microorganisms as biocontrol agents against fungal phytopathogens and mycotoxins. Biocontrol Sci. Technol., 2017; 28(1): 77-93. https:// doi.org/10.1080/09583157.2017.1419164 